\title{
Valor energético do capim-elefante em diferentes idades de rebrota e estimativa da digestibilidade in vivo da fibra em detergente neutro
}

\author{
[Energy value of elephantgrass at different regrowth ages and estimate of in vivo \\ neutral detergent fiber digestibility] \\ P.A. Silva ${ }^{1}$, S.C. Valadares Filho ${ }^{1 *}$, R.F.D. Valadares $^{2}$, P.R. Cecon $^{3}$, E. Detmann ${ }^{1}$, M.L. Paixão ${ }^{1}$ \\ ${ }^{1}$ Departamento de Zootecnia - UFV \\ Av. P.H. Rolfs, $\mathrm{s} / \mathrm{n}$ \\ 36571-000 - Viçosa, MG \\ ${ }^{2}$ Departamento de Veterinária - UFV - Viçosa, MG \\ ${ }^{3}$ Departamento de Informática - UFV - Viçosa, MG
}

\begin{abstract}
RESUMO
Comparou-se o valor energético do capim-elefante, obtido em diferentes idades de rebrota, com aqueles estimados pelas equações do National Research Council (NRC) e avaliou-se o tempo de incubação da fibra em detergente neutro (FDN) que representa a digestibilidade in vivo. A avaliação do capim ocorreu nas idades de 33, 48, 63, 78 e 93 dias de rebrota, utilizando-se quatro bovinos castrados, com peso médio inicial de $320 \mathrm{~kg}$. O procedimento de validação dos parâmetros foi realizado por meio do ajuste do modelo de regressão linear simples dos valores estimados sobre os observados. Realizou-se um ensaio de degradação in situ utilizando-se os tempos de 6,12,24, 36, 48, 72, 96, 120 e 144 horas para a determinação da degradabilidade da matéria seca (MS) e da fibra em detergente neutro (FDN). As frações digestíveis da FDN, a proteína bruta (PB), o extrato etéreo (EE) e os valores de NDT foram subestimados pelas equações do NRC, enquanto as dos carboidratos não fibrosos (CNF) foram semelhantes aos valores observados. $\mathrm{O}$ tempo de incubação in situ que melhor representou a digestibilidade in vivo da FDN foi o de 72 horas. Concluiu-se que as equações do NRC não foram eficientes na estimativa do valor energético do capim-elefante. Sugere-se a incubação in situ durante 72 horas para determinação da fração digestível da FDN.
\end{abstract}

Palavras-chave: capim-elefante, valor energético, degradabilidade, nutrientes digestíveis totais, equações

\begin{abstract}
This work was carried out to compare the energy (TDN) value of elephantgrass harvest at different regrowth ages with those estimated by NRC equations and evaluate neutral detergent fiber (NDF) incubation time, that represents in vivo digestibility. Four steers with average initial weight of $320 \mathrm{~kg}$ were fed elephantgrass harvested at 33, 48, 63, 78 and 93 regrowth ages. Energy value of elephantgrass at different ages was calculated by using chromic oxide to obtain fecal dry matter production, and NDT values were estimated by NRC equations. Parameter validation method was obtained by fitting the simple linear regression model on the observed values. An in situ degradation trial, by using incubation times of 6,12, 24, 36, 48, 72, 96, 120 and 144 hours, was performed to determine dry matter (DM) and neutral detergent fiber (NDF) degradability. $N D F$, crude protein $(C P)$ and ether extract (EE) digestible fractions and NDT values were underestimated by NRC equations, and nonfiber carbohydrates (NFC) values were similar to the observed ones. The best correlation between in situ incubation time and in vivo NDF digestibility was at 72 hours. NRC equations were not efficient to estimate elephantgrass energy value. It is suggested the in situ incubation for 72 hours to determine NDF digestible fraction of elephantgrass.
\end{abstract}

Keywords: elephantgrass, energy value, degradability, total digestible nutrients, equations

Recebido em 6 de setembro de 2005

Aceito em 18 de maio de 2007

*Autor para correspondência (corresponding author)

E-mail: scvfilho@ufv.br

Apoio: FAPEMIG 


\section{INTRODUÇÃO}

A energia é o nutriente que mais limita o desempenho dos ruminantes, merecendo, assim, especial atenção dos nutricionistas em relação às exigências do animal e à sua disponibilidade nos alimentos (Valadares Filho et al., 2003). A dificuldade de se avaliar a disponibilidade energética e a importância de se conhecer o conteúdo de energia dos alimentos tem levado ao desenvolvimento de métodos para estimar o conteúdo e a disponibilidade energéticos.

Estimativas acuradas da disponibilidade da energia contida nos alimentos são necessárias para formular dietas e avaliar o valor nutricional e econômico dos alimentos.

Segundo o NRC (Nutrient..., 1989), o sistema de energia líquida (EL) fornece valores de disponibilidade de energia muito mais precisos que os nutrientes digestíveis totais (NDT), mas este sistema ainda permanece porque os valores de EL são de difícil obtenção e também porque há grande quantidade de informações disponíveis sobre NDT. De acordo com Valadares Filho (2000), considerando que a grande parte da avaliação energética dos alimentos baseia-se no NDT, e que os cálculos de EL são estimados a partir do NDT ou da energia metabolizável (EM) oriunda também do NDT, o NDT deve ser considerado, no momento, como uma unidade possível de ser utilizada para formulação de rações.

O NRC (Nutrient..., 2001) propôs um método somativo para estimativa do NDT dos alimentos, com o consumo de matéria seca ao nível de mantença, usando a energia produzida pelas frações químicas do alimento, medida ou calculada por meio de análise de laboratório e de suas digestibilidades verdadeiras, por meio de equações (Costa, 2002). No Brasil, essas equações deverão ser validadas antes de serem recomendadas para estimar o valor energético dos alimentos produzidos em condições tropicais, principalmente dos volumosos e, especialmente, no que diz respeito à digestibilidade da fibra em detergente neutro (FDN; Rocha Júnior, 2002).

Ainda, o NRC (Nutrient..., 2001) sugere que a digestibilidade dos alimentos pode ser reduzida em função do aumento no consumo. Assim, propôs um fator de desconto que deveria ser aplicado na energia digestível de mantença (ED $\left.D_{\text {mantença }}\right)$ obtida pela equação: $E_{\text {mantença }}$ $(\mathrm{Mcal} / \mathrm{kg})=((\mathrm{PBD} / 100) * 5,6+(\mathrm{AGD} / 100) * 9,4+$ $(\mathrm{CNF} / 100) * 4,2+(\mathrm{FDN} / 100) * 4,2) \quad-0,3$, corrigindo-a para o efeito de consumo sobre a digestibilidade.

A equação para o cálculo do fator de desconto: $\mathrm{FC}=\mathrm{NDT}-\left((0,18 \mathrm{NDT}-10,3)^{*}\right.$ nível de ingestão)/NDT indica que o declínio em digestibilidade depende do consumo de matéria seca acima da mantença e da digestibilidade da dieta na mantença. Segundo o NRC (Nutrient..., 2001), para gado de leite, abaixo de $60 \%$ de $\mathrm{NDT}_{\text {mantença }}$ e desconto seria desnecessário.

Os objetivos deste trabalho foram comparar os valores observados e estimados do NDT e das frações digestíveis do capim-elefante e estimar o tempo de incubação in situ da FDN que melhor representa sua digestibilidade in vivo.

\section{MATERIAL E MÉTODOS}

O trabalho foi realizado nos meses de novembro de 2002 a fevereiro de 2003. Foram determinados os teores de NDT do capimelefante em diferentes idades de rebrota, utilizando-se quatro bovinos mestiços, com grau de sangue predominantemente Holandês, fistulados no rúmen, castrados, com aproximadamente $320 \mathrm{~kg}$. Os animais, mantidos em regime de confinamento, foram alojados em baias individuais cobertas.

Uma capineira cultivada com capim-elefante (Pennisetum purpureum schum.) cv. Cameroon, freqüentemente exposta à adubação orgânica, foi submetida a um corte de uniformização em $31 / 10 / 2002$ e imediatamente adubada com $500 \mathrm{~kg}$ de adubo granulado NPK (20-05-20) por ha. O capim foi avaliado aos 33, 48, 63, 78 e 93 dias de rebrota, idades estas correspondentes às médias dos seis dias de coleta de amostras, ou seja, a idade média de 33 dias foi obtida no período de digestibilidade conduzido com a planta entre 30 e 35 dias de rebrota.

A alimentação foi fornecida duas vezes ao dia, às 7 e $15 \mathrm{~h}$ e consistiu exclusivamente de capimelefante picado. As sobras foram previamente recolhidas e pesadas, durante o período de coletas, para determinação do consumo diário. A 
quantidade de ração fornecida foi calculada de modo a permitir $5 \%$ de sobra. $\mathrm{O}$ acesso ao sal mineral e à água foi irrestrito.

O período experimental teve duração de 15 dias, sendo nove de adaptação e seis de coleta, adotando-se procedimentos de rotina para experimentos dessa natureza. O óxido crômico $\left(\mathrm{Cr}_{2} \mathrm{O}_{3}\right)$ foi utilizado como indicador para a estimativa da produção de matéria seca fecal. A coleta de fezes foi realizada com intervalos de $22 \mathrm{~h}$, iniciando às $18 \mathrm{~h}$ do primeiro dia e terminando às $8 \mathrm{~h}$ do sexto dia. Adotaram-se também procedimentos de rotina na manipulação das amostras de fezes.

A análise de cromo nas fezes foi realizada de acordo com a técnica proposta por Willians et al. (1962), citados por Silva e Queiroz (2002). A matéria seca (MS), matéria orgânica (MO), nitrogênio total, extrato etéreo (EE), fibra em detergente neutro (FDN) do alimento, das sobras e das fezes e determinação de fibra em detergente ácido (FDA) e lignina dos alimentos foram determinados conforme Silva e Queiroz (2002). Os teores de compostos nitrogenados insolúveis em detergente neutro (NIDN) e em detergente ácido (NIDA) do alimento foram estimados nos resíduos obtidos após a extração das amostras nos detergentes neutro e ácido, respectivamente, por meio do procedimento de Kjeldahl, sendo a FDN dos alimentos corrigida para os níveis de cinzas e proteína, obtendo-se a fibra em detergente neutro isenta de cinzas e proteínas (FDNcp). A composição química e bromatológica do capim-elefante, nas diferentes idades de rebrota, pode ser observada na Tab 1.

Tabela 1. Composição química e bromatológica do capim-elefante nas diferentes idades de rebrota

\begin{tabular}{lccccc}
\hline \multirow{2}{*}{ Itens } & \multicolumn{5}{c}{ Dias de rebrota } \\
\cline { 2 - 5 } & 33 & 48 & 63 & 78 & 93 \\
\hline MS(\%) & 9,20 & 9,71 & 13,46 & 15,51 & 17,51 \\
MO $^{1}$ & 86,52 & 86,54 & 88,48 & 89,70 & 89,64 \\
PB $^{1}$ & 14,10 & 9,20 & 7,80 & 5,32 & 5,18 \\
PIDN $^{2}$ & 34,50 & 35,81 & 47,54 & 47,01 & 39,17 \\
PIDA $^{2}$ & 11,03 & 15,23 & 14,82 & 18,64 & 16,68 \\
EE $^{1}$ & 2,78 & 2,09 & 2,11 & 2,28 & 2,42 \\
FDN $^{1}$ & 60,62 & 63,47 & 67,68 & 69,58 & 69,23 \\
FDNcp $^{1}$ & 53,77 & 58,80 & 61,87 & 65,44 & 64,97 \\
CNF $^{1}$ & 10,51 & 12,17 & 10,93 & 13,26 & 12,81 \\
CNF $^{1}{ }^{1}$ & 17,36 & 16,84 & 16,74 & 17,40 & 17,07 \\
FDA $^{1}$ & 39,23 & 40,69 & 43,93 & 45,53 & 47,11 \\
Lignina $^{1}$ & 5,67 & 6,08 & 6,42 & 6,48 & 6,66 \\
\hline
\end{tabular}

Porcentagem da matéria seca; ${ }^{2}$ porcentagem da proteína bruta; MS - matéria seca; MO - matéria orgânica; PB - proteína bruta; PIDN - proteína insolúvel em detergente neutro; PIDA - proteína insolúvel em detergente ácido; EE - extrato etéreo; FDN - fibra em detergente neutro; FDNcp - fibra em detergente neutro corrigida para cinzas e proteína; CNF - carboidratos não fibrosos; CNFcp - carboidratos não fibrosos calculados com FDNcp; FDA - fibra em detergente ácido.

Os carboidratos não fibrosos (CNF) foram calculados pela equação proposta por Weiss (1999). O teor de nutrientes digestíveis totais observado (NDT observado) foi calculado por $\mathrm{NDT}=\mathrm{PBD}+2,25 \mathrm{EED}+\mathrm{FDNcpD}+\mathrm{CNFD}$, em que PBD, EED, FDNcpD e CNFD significam, respectivamente, proteína bruta digestível, extrato etéreo digestível, fibra em detergente neutro (isenta de cinzas e proteína) digestível e carboidratos não fibrosos digestíveis. A partir da composição do capim-elefante nas diferentes idades avaliadas, foram estimados os valores de $\mathrm{NDT}_{\text {mantença, conforme equações }}$ recomendadas pelo NRC (Nutrient..., 2001), que estima os teores de proteína bruta digestível (PBD), ácidos graxos digestíveis (AGD), fibra em detergente neutro isenta de proteínas digestível (FDNp) e carboidratos não fibrosos digestíveis (CNFD). A digestibilidade verdadeira da $\mathrm{PB}$, do $\mathrm{EE}$ e dos CNF foi corrigida para excreção fecal metabólica para cada nutriente, segundo os valores utilizados por Weiss et al. (1992) e adotados pelo NRC (Nutrient..., 2001). Dessa forma, os valores estimados a partir das equações foram subtraídos em 2,7; 1,4 e 3,1 unidades percentuais para a PBD, o EED e os CNFD, respectivamente. 
A validação das equações do NRC, para estimar as frações digestíveis dos nutrientes e dos nutrientes digestíveis totais (NDT) foi realizada a partir da comparação dos valores observados in vivo, com os valores estimados por meio de equações. O procedimento de validação das equações foi feito por intermédio do ajuste de modelo de regressão linear simples dos valores preditos sobre os observados, de acordo com o seguinte modelo: $\mathrm{Y}_{\mathrm{i}}=$ $\beta_{1} X_{i}+e_{i}$, em que $Y_{i}=$ valor de NDT predito; $\beta_{1}=$ coeficiente de inclinação da reta; $X i=$ NDT observado e ei $=$ erro aleatório, associado a cada observação.

No caso da rejeição da hipótese de nulidade, verifica-se a presença do vício global de estimação (VGE). O vício global de estimação é estimado como: $\operatorname{VGE}=\left(\hat{\beta}_{1}-1\right) * 100$, em que $\hat{\beta}_{1}=$ estimativa do coeficiente angular da equação de regressão e " 1 " é o valor paramétrico para o coeficiente angular sob a pressuposição de $\mathrm{H}_{0}$ ser verdadeira. Para todos os procedimentos estatísticos descritos, adotou-se $\alpha=0,05$.

Realizaram-se dois ensaios de degradação in situ, o primeiro para determinar o efeito do tamanho da partícula incubada, 1 ou $2 \mathrm{~mm}$, o segundo para determinar as degradabilidades da MS e da FDN e estimar com qual tempo de incubação in situ a digestibilidade in vivo da FDN melhor se correlaciona. No primeiro ensaio, foi utilizado capim-elefante com aproximadamente 40 dias de rebrota, picado e seco em estufa a $60^{\circ} \mathrm{C}$ e moído em moinho com peneira de 1 e $2 \mathrm{~mm}$. Sua composição química e bromatológica é apresentada na Tab. 2.

Os tempos de incubação foram de $0,6,12,24$, 36, 48, 72, 96, 120 e 144 horas. As amostras foram incubadas em dois animais, determinandose a FDN conforme Silva e Queiroz (2002). Posteriormente, os valores foram comparados mediante o ajuste de modelo de regressão linear simples dos valores de digestibilidade a $1 \mathrm{~mm}$ sobre os valores a $2 \mathrm{~mm}$.

Um segundo ensaio de degradabilidade foi realizado após o último período experimental, com dois dos quatro animais utilizados no experimento, quando estes ainda se alimentavam de capim-elefante. Utilizaram-se sacos de náilon de $10 \times 20 \mathrm{~cm}$, com porosidade de $50 \mu 1$, onde se adicionaram aproximadamente $5 \mathrm{~g}$ de amostra de capim-elefante para as respectivas idades avaliadas. Os tempos de incubação utilizados foram de $0,6,12,24,36,48,72,96,120$ e 144 horas. As amostras foram incubadas através da fístula ruminal, calculando-se a FDN dos resíduos da incubação. A degradabilidade da MS foi calculada utilizando-se o modelo de crescimento assintótico de primeira ordem, "reparametrizado" por Orskov e McDolnald (1979). Para a degradabilidade da FDN, utilizouse o modelo exponencial decrescente proposto por Mertens e Loften (1980). As degradabilidades in situ da FDN nas diferentes idades de rebrota, para todos os tempos avaliados, foram comparadas com a digestibilidade in vivo da FDN. Essa comparação foi feita por intermédio do modelo de regressão linear simples dos valores de digestibilidade da FDN in vivo sobre os valores in situ.

Tabela 2. Composição química e bromatológica do capim-elefante com 40 dias de rebrota

\begin{tabular}{lc}
\hline Item & Composição \\
\hline $\mathrm{MS}(\%)$ & 10,92 \\
$\mathrm{MO}^{1}$ & 85,81 \\
$\mathrm{~PB}^{1}$ & 12,18 \\
$\mathrm{PIDN}^{2}$ & 28,52 \\
$\mathrm{PIDA}^{2}$ & 9,31 \\
$\mathrm{EE}^{1}$ & 1,65 \\
$\mathrm{FDN}^{1}$ & 67,89 \\
$\mathrm{FDNcp}^{1}$ & 63,00 \\
$\mathrm{CNF}^{1}$ & 4,09 \\
$\mathrm{CNF}^{1} \mathrm{cp}$ & 8,98 \\
FDA $^{1}$ & 46,16 \\
LIGNINA $^{1}$ & 6,45 \\
\hline
\end{tabular}

${ }^{1}$ Porcentagem da matéria seca; ${ }^{2}$ porcentagem da proteína bruta; MS - matéria seca; MO - matéria orgânica; PB proteína bruta; PIDN - proteína insolúvel em detergente neutro, PIDA - proteína insolúvel em detergente ácido; EE extrato etéreo; FDN - fibra em detergente neutro; FDNcp fibra em detergente neutro corrigida para cinzas e proteína; $\mathrm{CNF}$ - carboidratos não fibrosos; $\mathrm{CNF} c p$ - carboidratos não fibrosos calculados com FDNcp; FDA - fibra em detergente ácido.

\section{RESULTADOS E DISCUSSÃO}

Os valores de NDT e os preditos pelo NRC (Nutrient..., 2001), para o capim-elefante nas idades de rebrota avaliadas são apresentados na Tab. 3. As estimativas do parâmetro $\beta_{1}$, bem como os coeficientes de determinação $\left(\mathrm{R}^{2}\right)$ da equação de regressão obtida a partir das comparações dos valores de NDT observados com os preditos pelo NRC (Nutrient..., 2001) 
foram respectivamente, 0,8558 e 0,9918 . O coeficiente de inclinação da reta $\left(\hat{\beta}_{1}\right)$ diferiu estatisticamente de $1(\mathrm{P}<0,05$; teste $\mathrm{t})$ para a variável analisada, indicando que os valores de NDT observados foram diferentes dos estimados pelas equações do NRC; e essa diferença foi mais acentuada quando a planta era mais jovem.

Para este experimento, os valores de NDT não foram corrigidos para o nível de consumo, uma vez que em quase todas as idades o NDT não ultrapassou $60 \%$. Se estes valores fossem corrigidos, as diferenças entre NDT observado e estimado seriam ainda maiores.

Tabela 3. Valores de nutrientes digestíveis totais (NDT; \%) observados no experimento e preditos pelo NRC, para o capim-elefante, em diferentes idades de rebrota

\begin{tabular}{ccc}
$\begin{array}{c}\text { Idades de } \\
\text { rebrota }\end{array}$ & $\begin{array}{c}\text { NDT } \\
\text { observado }\end{array}$ & $\begin{array}{c}\text { NDT } \\
\text { estimado }\end{array}$ \\
\hline 33 & 68,89 & 54,40 \\
48 & 64,04 & 50,45 \\
63 & 58,50 & 50,84 \\
78 & 58,68 & 51,95 \\
93 & 55,22 & 51,32 \\
\hline
\end{tabular}

${ }^{1}$ Nutrient... (2001).

Costa (2002), ao utilizar diferentes alimentos volumosos e concentrados, não observou diferença significativa entre valores preditos e estimados de NDT, tanto para alimentos volumosos quanto para concentrados ou o conjunto de volumosos e concentrados. Para o capim-elefante, este autor encontrou valores de NDT observado e estimado de 46,72 e 48,92, respectivamente. $\mathrm{O}$ valor estimado foi corrigido para o nível de consumo, utilizando-se um fator de 0,95 .
Rocha Júnior et al. (2003), ao avaliarem a eficácia das equações propostas pelo NRC, a partir da comparação dos valores preditos e observados em um experimento com ovinos e de uma coletânea de valores de NDT obtidos na literatura nacional a partir de experimentos in vivo, concluíram que as equações seriam adequadas para predizer o valor energético dos alimentos em condições brasileiras. Vale ressaltar que esses autores também trabalharam, in vivo, no experimento com ovinos, utilizandose volumosos e concentrados combinados.

$\mathrm{Na}$ Tab. 4 pode-se observar a estimativa das frações digestíveis dos nutrientes observadas na digestibilidade in vivo e estimadas pelo NRC (Nutrient..., 2001) e na Tab. 5, são apresentadas as estimativas do parâmetro $\beta^{1}$, bem como os coeficientes de determinação das equações de regressão obtidas a partir das comparações entre as frações digestíveis dos nutrientes observadas e estimadas. As frações digestíveis da FDN, do EE e da PB foram subestimadas $(\mathrm{P}<0,05)$ pelas equações do NRC. Somente a fração digestível do CNF não apresentou diferença entre valores preditos e estimados.

A maior diferença entre valores preditos e observados da fração FDND ocorreu quando a planta era mais jovem, comportamento semelhante ao verificado para a diferença observada entre os valores preditos e observados do NDT, demonstrando a importância de um valor confiável da fração digestível da FDN na determinação do NDT estimado pelas equações do NRC. Essa importância justifica-se pelo fato de a FDN ser a maior fração constituinte das gramíneas tropicais.

Tabela 4. Frações digestíveis (D) da proteína bruta (PB), extrato etéreo (EE), fibra em detergente neutro corrigida para cinza e proteína (FDNcp) e carboidratos não fibrosos (CNF) para o capim-elefante nas diferentes idades de rebrota, observadas por meio da digestibilidade in vivo e estimadas pelas equações do $\mathrm{NRC}^{1}$

\begin{tabular}{ccccccccc}
\hline $\begin{array}{c}\text { Idade de } \\
\text { rebrota }\end{array}$ & PBD $^{1}$ & PBD $^{2}$ & EED $^{1}$ & EED $^{2}$ & FDNcpD $^{1}$ & FDNcpD $^{2}$ & CNFD $^{1}$ & CNFD $^{2}$ \\
\hline 33 & 10,64 & 9,65 & 2,43 & 0,38 & 38,97 & 28,03 & 13,71 & 13,91 \\
48 & 6,09 & 4,96 & 1,64 & 0,00 & 40,97 & 30,84 & 13,15 & 13,40 \\
63 & 5,09 & 3,83 & 1,53 & 0,00 & 37,51 & 32,41 & 12,33 & 13,31 \\
78 & 2,74 & 1,55 & 1,76 & 0,00 & 38,93 & 34,76 & 12,69 & 13,95 \\
93 & 2,45 & 1,54 & 2,03 & 0,02 & 34,60 & 34,16 & 12,71 & 13,63 \\
\hline
\end{tabular}

${ }^{\mathrm{T}}$ Nutrient... (2001), ${ }^{2}$ valores observados; ${ }^{3}$ valores estimados. 
Tabela 5. Estimativa dos coeficientes $\left(\beta_{1}\right)$ das equações de regressão entre os valores das frações digestíveis (D) da proteína bruta (PB), extrato etéreo (EED), fibra em detergente neutro (FDND) e carboidratos não fibrosos (CNFD), observadas e preditas pelas equações do $\mathrm{NRC}^{1}$

\begin{tabular}{lcc}
\multirow{2}{*}{ Variável } & \multicolumn{2}{c}{ Coeficiente de inclinação } \\
\cline { 2 - 3 } & Estimativa & $\mathrm{R}^{2}$ \\
\hline $\mathrm{PBD}^{3}$ & $0,8378^{*}$ & 0,9650 \\
$\mathrm{EED}^{3}$ & $0,0602^{*}$ & 0,3951 \\
$\mathrm{FDND}^{3}$ & $0,8347^{*}$ & 0,9871 \\
$\mathrm{CNFD}^{3}$ & $1,0905^{\text {ns }}$ & 0,9924 \\
\hline
\end{tabular}

${ }^{1}$ Nutrient... (2001). ${ }^{2}$ Regressão: $\mathrm{Y}=\beta 1 \mathrm{X} ;{ }^{3} \mathrm{Capim}$-elefante em diferentes idades de rebrota; $*$ significativo pelo teste t a $5 \%$ de probabilidade; ${ }^{\text {ns }}$ não significativo.

Rocha Junior (2002) não observou diferença significativa entre valores observados e estimados de PBD e CNFD para alimentos volumosos, quando trabalhou com ovinos, utilizando a coleta total de fezes para determinação da digestibilidade in vivo. Para as frações digestíveis do EE e da FDN este autor verificou que as equações propostas pelo NRC (Nutrient..., 2001) subestimaram tais frações.

A comparação entre os valores de degradação da FDN utilizando-se partículas de 1 ou $2 \mathrm{~mm}$ está apresentada na Tab. 7. A estimativa do coeficiente $\beta_{1}$ das equações de regressão e do coeficiente de determinação obtidas a partir das comparações dos valores de degradação da fibra em detergente neutro (DGFDN) observadas para o capim-elefante a $1 \mathrm{~mm}$ e $2 \mathrm{~mm}$ foram 1,0064 (ns) e 0,9998, respectivamente. Não se verificou diferença significativa entre os valores utilizando-se os dois tamanhos de partículas, assim, o outro ensaio foi realizado com partículas a $2 \mathrm{~mm}$.

Tabela 6 - Valores de degradação da fibra em detergente neutro (DGFDN) observados para o capim-elefante com 40 dias de rebrota, utilizando-se partículas de 1 ou $2 \mathrm{~mm}$, nos respectivos tempos de incubação

\begin{tabular}{ccc}
\hline \multirow{2}{*}{ Tempo } & \multicolumn{2}{c}{ Partícula } \\
\cline { 2 - 3 } 0 & $1 \mathrm{~mm}$ & $2 \mathrm{~mm}$ \\
\hline 6 & 2,00 & 1,23 \\
12 & 4,86 & 4,25 \\
24 & 10,50 & 11,16 \\
36 & 24,63 & 25,62 \\
48 & 36,92 & 37,65 \\
72 & 49,29 & 48,73 \\
96 & 56,19 & 57,12 \\
120 & 60,92 & 61,65 \\
144 & 64,65 & 64,92 \\
\hline
\end{tabular}

Na Tab. 7 encontram-se as estimativas da fração solúvel (a), da fração potencialmente degradável (b) e da taxa de degradação b $(\mathrm{Kd})$ das equações ajustadas para a degradabilidade da MS e a estimativa da fração potencialmente degradável (b), da fração indigestível (i), do tempo de latência (L) e a taxa de degradação da fração b das equações ajustadas para a degradabilidade da FDN. Houve redução nas taxas de degradação tanto para a MS quanto para a FDN, à medida que as idades de rebrota foram maiores. Para a degradabilidade da FDN esse comportamento pode ser explicado pelo aumento da fração indigestível, representado por i.

Gomes (2004), ao trabalhar com o capimelefante em idade média de maturidade, observou valores próximos aos encontrados para a idade de 48 dias, para a degradação da MS de 20,$61 ; 46,89$; e 4,92 para os respectivos coeficiente a,b e $\mathrm{Kd}$ e para a degradação da FDN, 56,75; 3,02; 5,04; e 29,26 para os coeficientes b, Kd, L,e i, respectivamente. A maior degradabilidade da FDN ocorreu para as menores idades de rebrota 33 e 48 dias, onde os valores da fração insolúvel indigestível (i) foram menores, 23,95 e 25,69, respectivamente. Os valores obtidos de degradabilidade in situ nos tempos de 48, 72, $96 \mathrm{~h}$ e de digestibilidade in vivo da FDN, são apresentados na Tab. 8.

As estimativas dos coeficientes $\beta 1$ das equações de regressão entre os valores in vivo da digestibilidade da FDN sobre os valores in situ, durante 48, 72 e 96 h, estão apresentadas na Tab. 9. Pode-se observar que o tempo de incubação que melhor se correlacionou com a digestibilidade in vivo da FDN foi o de $72 \mathrm{~h}$.

Para as incubações in vitro, o NRC (Nutrient..., 2001) sugeriu que a fração digestível da FDN poderia ser obtida no tempo de 48 horas. Esse tempo, no entanto, não foi adequado para este experimento em condições de incubação in situ. Já que as equações do NRC não foram eficientes em predizer a fração digestível da FDN, sugerese, para o capim-elefante, que essa fração seja estimada pela incubação in situ durante 72 horas. 
Valor energético do capim-elefante...

Tabela 7. Estimativas dos coeficientes a $(\%), \mathrm{b}(\%), \mathrm{Kd}(\% / \mathrm{hora})$ das equações ajustadas para a degradabilidade da MS, estimativa dos coeficientes b (\%), Kd (\%/hora), i (\%) e L (horas) das equações ajustadas para a degradabilidade da FDN e respectivos coeficientes de determinação $\left(\mathrm{R}^{2}\right)$ para o capimelefante nas diferentes idades de rebrota

\begin{tabular}{|c|c|c|c|c|c|}
\hline \multirow[t]{2}{*}{ Idade de rebrota } & \multicolumn{4}{|c|}{ Degradabilidade da MS } & \multirow{2}{*}{$\mathrm{R}^{2}$} \\
\hline & $\mathrm{a}$ & & $\mathrm{b}$ & $\mathrm{Kd}$ & \\
\hline 33 & 28,77 & & 51,15 & 6,16 & 0,98 \\
\hline 48 & 23,92 & & 54,65 & 5,21 & 0,99 \\
\hline 63 & 17,57 & & 54,85 & 4,13 & 0,99 \\
\hline 78 & 16,85 & & 53,32 & 4,34 & 0,99 \\
\hline 93 & 18,51 & & 46,17 & 3,89 & 0,99 \\
\hline \multirow[t]{2}{*}{ Idade de rebrota } & \multicolumn{4}{|c|}{ Degradabilidade da FDN } & \\
\hline & $\mathrm{b}$ & $\mathrm{Kd}$ & $\mathrm{i}$ & $\mathrm{L}$ & $\mathrm{R}^{2}$ \\
\hline 33 & 51,03 & 3,083 & 23,95 & 6,52 & 0,98 \\
\hline 48 & 50,70 & 3,179 & 25,69 & 8,98 & 0,99 \\
\hline 63 & 52,45 & 2,972 & 32,17 & 7,83 & 0,99 \\
\hline 78 & 57,01 & 3,154 & 33,02 & 4,91 & 0,99 \\
\hline 93 & 45,97 & 2,501 & 38,31 & 8,56 & 0,99 \\
\hline
\end{tabular}

Tabela 8. Valores de degradabilidade in situ da FDN (DGFDN in situ) para os tempos de 48, 72 e $96 \mathrm{~h}$ e de digestibilidade in vivo da FDN, para o capim-elefante em diferentes idades de rebrota

\begin{tabular}{|c|c|c|c|c|}
\hline $\begin{array}{l}\text { Idade de } \\
\text { rebrota }\end{array}$ & in situ $48 \mathrm{~h}$ & in situ $72 \mathrm{~h}$ & in situ 96h & in vivo \\
\hline 33 & 66,91 & 72,30 & 75,35 & 72,48 \\
\hline 48 & 61,90 & 68,96 & 73,35 & 69,63 \\
\hline 63 & 50,44 & 59,24 & 63,20 & 60,62 \\
\hline 78 & 51,91 & 59,48 & 61,92 & 59,48 \\
\hline 93 & 46,19 & 54,46 & 58,63 & 53,25 \\
\hline
\end{tabular}

Tabela 9. Estimativa do coeficiente $\beta_{1}$ das equações de regressão dos valores de digestibilidade da FDN (DFDN) in vivo sobre os valores in situ nos tempos de 48, 72 e 96h, para o capim-elefante em diferentes idades de rebrota

\begin{tabular}{|c|c|c|}
\hline & \multicolumn{2}{|c|}{${ }^{1 /}$ Coeficiente de inclinação } \\
\hline & Estimativa & $\mathrm{r}^{2}$ \\
\hline DGFDN 48h/DFDN in vivo ${ }^{2 /}$ & $1,2329 *$ & 0,9988 \\
\hline DGFDN 72h/DFDN in vivo ${ }^{2 /}$ & $1,0037^{\mathrm{ns}}$ & 0,9998 \\
\hline DGFDN 96h/DFDN in vivo ${ }^{2 /}$ & $0,9498 *$ & 0,9994 \\
\hline
\end{tabular}

1/Regressão: $\mathrm{Y}=\beta 1 \mathrm{X} ; 2$ / Capim-elefante em diferentes idades de rebrota; *significativo pelo teste t ao nível de 5\% de probabilidade, ${ }^{\text {ns }}$ não significativo.

\section{CONCLUSÕES}

Os valores de NDT obtidos a partir da equação proposta pelo NRC foram incompatíveis com os valores observados para o capim-elefante. As frações digestíveis da FDN, PB e EE não foram estimadas de maneira adequada pelas equações do NRC; na determinação da fração digestível da
FDN sugere-se a incubação in situ durante 72 horas. Os valores de degradação da FDN são satisfatoriamente obtidos utilizando-se 1 ou $2 \mathrm{~mm}$ de tamanho de partícula. $\mathrm{O}$ aumento da idade de rebrota do capim se reflete em maiores valores para a fração indigestível e conseqüentemente redução nas taxas de degradação da FDN. 


\section{REFERÊNCIAS BIBLIOGRÁFICAS}

COSTA, M.A.L. Desempenho de novilhos zebuinos e validação das equações do NRC (2001) para predizer $o$ valor energético dos alimentos nas condições brasileiras. 2002. 80f. Dissertação (Mestrado). Universidade Federal de Viçosa, Viçosa, MG.

GOMES, S.P. Contaminação Salivar da Extrusa, Consumo, Digestibilidade e Produção Microbiana em Novilhos Alimentados com Diferentes dietas. 2004. 56f. Dissertação (Mestrado) - Universidade Federal de Viçosa, Viçosa, MG

MERTENS, D.R.; LOFTEN, J.R. The effect of starch on forage fiber digestion in vitro. J. Dairy Sci, v.63, p.1437-1446, 1980.

NUTRIENT requirements of dairy cattle. 6ed. Washington, DC: National Academic, 1989. 158p.

NUTRIENT requeriments of dairy cattle. 7.ed. Washinton, DC: National Academic, 2001. 381p.

ORSKOV, E.R.; McDONALD, I. The estimation of protein degradability in the rumen from incubation measurements weighted according to rate of passage. J. Agric. Sci., v.92, p.499-503, 1979.

ROCHA JÚNIOR, V.R. Tabelas brasileiras de composição de alimentos, determinação e estimação do valor energético dos alimentos para ruminantes. 2002. 2521f. Tese (Doutorado) - Universidade Federal de Viçosa, Viçosa, MG.
ROCHA JÚNIOR, V.R.; VALADARES FILHO, S.C.; BORGES, A.M. et al. Estimativa do valor energético dos alimentos e validação das equações propostas pelo NRC 2001. Rev. Bras. Zootec., v.32, p.480-490, 2003.

SILVA, D.J.; QUEIROZ, A.C. Análise de alimentos: métodos químicos e biológicos. 3.ed. Viçosa: Editora UFV, 2002. 235p.

VALADARES FILHO, S.C. Nutrição, avaliação de alimentos e tabelas de composição de alimentos para bovinos. In: REUNIÃO ANUAL DA SOCIEDADE BRASILEIRA DE ZOOTECNIA, 37. 2000, Viçosa. Anais... Viçosa:UFV, 2000. p. 267-338.

VALADARES FILHO, S.C.; SILVA, P.A.; ROCHA JÚNIOR, V.R. et al. Estimativa do valor energético dos alimentos em condições tropicais. Volumosos na Produção de Ruminantes. Jaboticabal, SP: Editora Funep, 2003. 264p.

WEISS, W.P.; CONRAD, H.R.; PIERRE, N.R.St. A theoretically-based model for predicting total digestible nutrient values of forages and concentrates. Anim. Feed Sci. Technol., v.39, p.95-110, 1992.

WEISS, W.P. Energy prediction equations for ruminant feeds. In: CORNELL NUTRITION CONFERENCE FOR FEED MANUFACTURERS, 61., 1999. Proceeding..., Ithaca: Cornell University, 1999. p. 176-185. 